\title{
O conceito de ethos na música da Antiguidade Clássica grega
}

The concept of ethos in Ancient Greek music

Tales Pimentel Portugal talespportuga@hotmail.com

Antenor Ferreira Corrêa antenorfc@unb.br 


\section{Resumo}

No presente texto, apresentamos considerações sobre o conceito de ethos no ideário da Antiguidade Clássica. Duas obras foram tomadas como ponto de partida para essas considerações: $A$ república de Platão e $A$ política de Aristóteles. A partir do confronto entre esses dois filósofos foi possivel discorrer sobre a maneira como concebiam a transmissão de emoções e o impacto no caráter dos cidadãos causado pela música, bem como a transformação do posicionamento de ambos em relação à função da música na sociedade. No âmbito dessa argumentação, concluímos que a compreensão mais ampla do conceito de ethos é primordial para o entendimento do pensamento musical dos autores e compositores desde a Antiguidade Clássica até, no mínimo, a Renascença.

Palavras-chave: ethos, modos gregos, música na Grécia antiga, modos eclesiásticos.

\section{Abstract}

In this paper, the concept of ethos is considered as pertaining to the precepts of Ancient Greece. Two works were taken as a starting point for these considerations: The Republic by Plato, and Politics by Aristotle. By comparing these two philosophers, a discussion was made possible which showed their conception of music's impact on the placement of emotions and on the character of citizens, as well as the philosophers' changing opinions in relation to the role of music in society. In the context of this discussion, we conclude that a broader comprehension of ethos is central to the understanding of composers' musical thought from Classical Antiquity, at least up to the Renaissance.

Keywords: ethos, Greek modes, music in Ancient Greece, church modes. 


\section{Introdução}

Trataremos do conceito de ethos na Antiguidade Clássica ${ }^{1}$, abordando as características gerais associadas a esse conceito bem como sua importância para a sociedade. Será considerado o sentido filosófico, a relação com a música e os posicionamentos de Platão e Aristóteles em relação à utilização desse termo. Comentaremos, também, a forma como esses filósofos discutiram sobre a manipulação de elementos da música para a transmissão do ethos com intuito de formarem o caráter do cidadão. Ethos é um conceito importante para se compreender os fundamentos da ética na sociedade da Grécia Antiga, pois, como explicaremos adiante, trata-se este do comportamento habitual do ser humano na sociedade. Na sua relação com a ética, ethos indicava aquilo aceito socialmente, ou seja, advertia sobre a norma de conduta e do bom comportamento social. "Hesíodo usou-o primeiramente como 'costume'" (ANDERSON; MATHIESEN 2016, 凤[2]; tradução minha). ${ }^{2}$ Estes musicólogos, autores do verbete "ethos" em The new Grove dictionary of music and musicians (2. ed., reproduzido no site da internet), também indicam esse sentido original de ethos como lugar de costume ("accustomed place") que expressa um costume ou hábito (ANDERSON; MATHIESEN 2016, ๆ[2]). Segundo eles, Heráclito utilizou o termo ethos significando 'caráter', "mais precisamente o 'caráter moral', normalmente aceito como resultado de [algo considerado] hábito" (ANDERSON; MATHIESEN, 2016, 9[2]). ${ }^{3}$ Entendemos, assim, que ethos refere-se às atitudes características e distintivas, os hábitos, crenças e convicções de um indivíduo ou de um grupo social particular. Aristóteles também incluiu o ethos como um dos três pilares do discurso retórico, a saber: ethos (o convencimento fundado na ética, onde o orador convence baseado no caráter e autoridade de alguém), pathos (o convencimento fundado no apelo à emoção, onde o orador intenta convencer pela resposta emocional que provoca na audiência) e logos (o convencimento fundamentado na lógica, onde o orador persuade pela razão).

A leitura dos autores clássicos, especificamente Platão e Aristóteles, permite um aprofundamento no conceito de ethos que configura-se, portanto, como uma base significativa para a compreensão da música da Renascença, uma vez que os ideais clássicos gregos foram "resgatados" nesse período. Ao lado desses dois filósofos, confrontaremos tratadistas e musicólogos que se detiveram sobre o estudo da música na Antiguidade grega, constituindo assim um apanhado de textos esparsos de maneira a facilitar futuras pesquisas sobre ethos e, quem sabe, motivar os pesquisadores brasileiros à composição de uma antologia sobre o tema.

\footnotetext{
1 "Formalmente, foi estabelecido que o ponto inicial da Era Clássica encontra-se no primeiro registro da poesia do grego Homero, nos séculos VIII-VII a.e.c. Já o seu término localiza-se ao final da chamada Antiguidade Tardia (300 a 600 e.c.), momento em que se inicia a Idade Média" (SANTIAGO, 2017, Т[2]).

2 "Hesiod first used it as 'custom".

3 "[M]ore precisely 'moral character', often regarded as the result of habituation".
} 


\section{Ethos nos escritos da Antiguidade Clássica}

De acordo com o dicionário Termos filosóficos gregos, ethos pode ser entendido como "caráter" ou "modo de vida habitual" (PETERS, 1983, p. 85), definição similar àquela citada acima. De acordo com Heráclito (535-475 a.e.c.), "o ethos de um homem é o seu daimon" (Diels apud. PETERS, 1983, p. 85). Daimon pode ser lido como "destino", mas era considerado no período como uma "presença ou entidade sobrenatural, algures entre um deus (theos) e um

Ethos "em Platão (428-347 a.e.c.) é o resultado do hábito" (PETERS, 1983, p. 85). Se partirmos do entendimento de Heráclito sobre ethos, veremos que Platão apenas identifica o daimon como as situações geradoras de caráter. Essas situações seriam interações familiares, de trabalho, maneiras de lidar com objetos e as situações cotidianas em geral. Por meio desse entendimento, a partir de Platão o ethos deixa de ser a aceitação sobrenatural do 'caráter' humano e passa a ser compreendido como o 'modo de vida habitual' do indivíduo.

Aristóteles aborda esse conceito ao afirmar que ethos "é mais moral do que intelectual" (PETERS, 1983, p. 85). Essa afirmação pode ser interpretada como a passagem de uma reflexão sobre o hábito (uma vez que intelecto implicava a faculdade de pensar) para a orientação do comportamento do indivíduo em sociedade. Isso se explica pela compreensão do conceito de moral, ou seja, o que concerne à ética e, portanto, relacionado à conduta, sendo esta dirigida e disciplinada por normas. Tendo isso em mente, o ethos permite ser interpretado em sua relação com o funcionamento de uma determinada sociedade. Deixa, portanto, de ser considerado um mero hábito desenvolvido durante o tempo de vida do cidadão e amplia-se para um contexto que une a convivência de uma época às condições de relações sociais que perduram por diferentes gerações. Assim sendo, Aristóteles mantém a compreensão acerca do ethos como hábito, mas entende que este deve estar regulado segundo uma ética e, assim, aplicado à sociedade como um todo.

Com isso, observamos a adaptação gradual do conceito, partindo da admissão do comportamento do indivíduo controlado por um ser externo, passando para o hábito do indivíduo em seu meio de convivência, até chegar ao entendimento de ethos como formação do caráter social pela regulação da conduta individual. Por conta disso, como se verá adiante, o conceito de ethos em música atende a uma proposição pedagógica ampla.

\section{Ethos e música}

David B. Monro inicia seu livro sobre os modos na Grécia antiga com uma afirmação importante para o entendimento do papel da música naquela sociedade:

Na Grécia antiga, haviam certos tipos ou formas de música, as quais eram conhecidas por nomes de nações ou tribos (Dóricos, Jônios, Frígios, Lídios, etc.), cada uma dessas era acreditada ser capaz não somente de expressar emoções particulares, mas de agirem sobre a sensibilidade de tal maneira a exercer uma influência poderosa e específica na formação do caráter. Consequentemente, a 
escolha dentre essa variedade de formas musicais daquelas que deveriam ser admitidas na educação do estado era questão da mais séria preocupação. (MONRO, 2012, p.20) ${ }^{4}$.

Constatações similares à de Monro podem ser encontradas em diversos livros sobre a música na sociedade da Grécia antiga. Este entendimento também é passível de ser inferido pela leitura de diálogos e fragmentos de textos remanescentes do período. Percebe-se, portanto, uma relação entre ethos e música de base ética que, como se verá, se desdobra para a orbe pedagógica. Na música, ethos deve ser entendido como um caráter que transmitido e moldado no ouvinte. Ethos, assim, implicava na utilização da música para a educação da alma ${ }^{5}$ ou formação da conduta ética. Os filósofos, a partir do século V a.e.c., como Pitágoras, Platão, Aristóteles, acreditavam que a música tinha influência na alma e o poder de moldar o caráter humano por meio da identificação que o indivíduo tinha com o ethos de dada música (ANDERSON; MATHIESEN, 2016). Luis Colomer e Begoña Gil, tradutores de Aristides Quintiliano, esclarecem que "a ação direta da música sobre a alma é uma das chaves para o entendimento da concepção musical grega". Segundo esses comentaristas, no pensamento platônico, "a alma é uma entidade intermediária entre o mundo das ideias e o mundo material" (1986, p.114, nota 3). Entretanto, como os filósofos gregos chegaram à proposição do ethos musical e sua consequentemente utilização? Como realizaram a correspondência entre as diferentes formas musicais e os respectivos ethos? Como a música pode afetar a alma e moldar o caráter? Essas questões serão retomadas a seguir nas seções sobre o ethos em Platão e Artistóteles.

De acordo com Anderson e Mathiesen (2016), data do início do século V a.e.c. a primeira descrição do poder do ethos na música. Esse ponto de vista tem uma relação estreita com o pensamento da escola pitagórica. A ideia principal é de que a música por meio de manipulação numérica e da relação proporcional entre os sons poderia afetar a alma e o caráter. Desse pensamento surgiram dois segmentos: 1) a utilização abstrata de relações harmônicas e valores cósmicos (obviamente, procedente da proposição de Pitágoras que por meio de seus experimentos com o monocórdio concebeu a unidade entre o número, a alma e o $\operatorname{cosmos}^{6}$ ) e 2) a expressão do belo e das sensações que a música poderia propiciar. Esse posicionamento foi advogado, entre outros, por Damon, filósofo da escola pitagórica (ANDERSON; MATHIESEN, 2016). Colomer e Gil, ao comentarem a passagem de Quintiliano na qual o mesmo discorre sobre o efeito da música na alma, também atestam a precedência histórica a Damon. Segundo esse

\footnotetext{
$4 \quad$ In ancient Greece there were certain kinds or forms of music, which were known by national or tribal names - Dorian, lonian, Phrygian, Lydian and the like: that each of these was believed to be capable, not only of expressing particular emotions, but of reacting on the sensibility in such a way as to exercise a powerful and specific influence in the formation of character and consequently that the choice, among these varieties, of the musical forms to be admitted into the education of the state, was a matter of the most serious practical concern.

5 "Todo corpo cujo movimento é imprimido de fora é inanimado, todo corpo que se move de per si, do seu interior, é animado; e essa é, precisamente, a natureza da alma" (ABBANAGNO, 1998, p. 28)

6 Para um estudo aprofundado dos experimentos de Pitágoras com o monocórdio e o impacto sobre as ciências vide: CREESE, David. The Monochord in Ancient Greek Harmonic Science. New York: Cambridge University Press, 2010.
} 
comentadores, "a aplicação concreta dos diferentes tipos de música para a formação e correção do ethos anímico parece dever-se a Damón (v a.C)" (1986, p.114, nota 2).

A utilização abstrata de relações harmônicas e valores cósmicos parte do pressuposto de que os números estão intimamente ligados à realidade e, na força da harmonia, os elementos do cosmos estão dispostos de forma a permitir que o homem tome posse da realidade, ou seja, compreenda o mundo a partir de seu intelecto. O entendimento da existência de sensações passíveis de transmissão na e pela música implica que a alma é afetada favorável ou desfavoravelmente pela atividade musical. Recai, ainda, sobre o processo musical o trabalho com o ritmo e, conforme Anderson e Mathiesen (2016), Damon foi o primeiro a aplicar valor moral aos ritmos utilizados.

Embora o conceito de ethos esteja presente nos escritos de vários filósofos e poetas da Grécia Antiga e de períodos seguintes, Anderson e Mathiesen (2016) enfatizam que, de acordo com uma visão Helenística, não existe uma "teoria do ethos" única ou coesa. A "Ethoslehre" ou "Lehre vom Ethos" (lit., "doutrina do ethos") foi desenvolvida por acadêmicos alemães (estas teorias não serão objeto de análise neste artigo, uma vez que nosso foco recai sobre a teoria dos filósofos da Grécia antiga). Os fatores que devem ser considerados para se detectar o ethos na música são: associação étnica ou literária (porque há certo entendimento entre os historiadores que grupos étnicos distintos possuíam padrões rítmicos característicos em suas poesias), situações religiosas, o tipo de modo e instrumentos utilizados. Com relação ao aspecto étnico, Monro traz uma interessante observação: "um termo tal como Dórico não foi aplicado aleatoriamente a um modo particular, mas porque aquele modo era distintivo da música Dórica; e a música Dórica, novamente, era um aspecto do temperamento e instituições Dóricas, literatura e pensamento Dóricos" (MONRO, 2012, p.158)7.

\section{Teoria musical na Grécia Antiga}

Para avançarmos no estudo do ethos, precisamos entender um pouco da teoria musical grega. Alguns aspectos dessa teoria serão aqui considerados tendo por ponto de partida o texto de Grout e Palisca (2001) e tratados sobre música, como os escritos por Aristides Quintiliano e Cleonides. No processo de entendimento musical e desenvolvimento dessa teoria grega da Antiguidade, os filósofos identificaram alguns conceitos específicos (elementos e estruturas), deduzidos a partir do repertório melódico (estritamente monofônico) da época: alturas, intervalos, gêneros de tetracordes, sistemas de modos (ou tonoi, veja abaixo). Baseado nesses conceitos, teremos o apoio para entender a estruturação do pensamento harmônico amplo vigente na doutrina grega e, consequentemente, mais próximos de entender o poder conferido aos modos na transmissão do ethos.

Os conceitos de nota e intervalo dependiam de uma diferenciação entre dois tipos de movimento da voz humana: contínuo, em que a voz mudava de altura sem se fixar em 
notas, e diastemático, em que o som era sustentado por tempo suficiente para tornar perceptíveis as notas na sua individualidade (Cf: Grout e Palisca, 2001, p.22). Aristides Quintiliano, por seu turno, afirma que "a matéria da música é a voz e o movimento do corpo" (p.44). Ou seja, o um corpo (prega vocal) posto em vibração (movimento) produz o som musical. Adiante, Quintiliano irá teorizar que o movimento pode ser identificado como simples ou não simples,. O movimento não simples, por sua vez, é dividido em contínuo, interválico e intermediário (p.45). Ele expõem:

(...) a voz contínua é a que se relaxa e se tenciona de maneira imperceptível por conta de sua velocidade. A voz interválica é a que possui alturas tonais claras e não permite perceber a passagem entre essa. A voz intermediária é a que consiste em uma combinação de ambas. Assim, a voz contínua é a que usamos na fala, voz intermediária é aquela que usamos para recitar poemas, e a voz interválica é a que faz paradas e intervalos de certa magnitude entre vozes simples. Esta voz interválica também se chama melódica (Quintilianus, 1986, p.45).

Alguns exemplos de intervalos musicais são: quarto de tom (díesis), semitom (dobro da díesis), tom (dobro do semitom), dítono (dobro do tom), semi-dítono (um tom mais um semitom, modernamente denominado terça menor), diatesaron (modernamente classificado como intervalo de quarta), diapente (modernamente classificado como quinta) e diapason (oitava justa). Os intervalos podem se combinar em três diferentes tipos básicos (gêneros) de tetracordes: diatônico, cromático e enarmônico. Essa classificação dos sons musicais é significativa, uma vez que o som entendido como a menor parte de uma voz melódica ao ser combinado em intervalos permitia diferenciação. Essa distinção não se dava somente pelo registro grave e agudo entre os sons, mas também pela sua participação na geração dos modos e, consequentemente, em todo os sistema harmónico, mas também pelo seu ethos particular.

Um aspecto do sistema musical importante no entendimento da ligação entre ethos e música são os chamados modos gregos. Modos dizem respeito à maneira de se ordenar os sons em uma seqüência padronizada de intervalos. Este tipo de ordenação, desde o período clássico, passou a ser chamado de escala. Tanto modo como escala ordenam uma série de alturas a partir de uma altura principal. Nos modos gregos essa altura principal era a nota inicial, mais aguda, do tetracorde. Nos modos eclesiásticos ou litúrgicos essa altura recebia o nome de finalis, e no sistema escalar maior/menor denomina-se tônica. Uma primeira distinção entre modo e escala está no fato de os modos comportarem intervalos menores que o semitom, uma vez que dependiam do gênero do tetracorde utilizado. Justamente por esse motivo, uma diferença marcante entre modo e escala reside no fato de os modos gregos serem constituídos a partir da junção de tetracordes (veja a seguir), gerando assim um sistema fixo, no qual os modos conservavam sempre suas notas principais, isto é, não havia transposição ${ }^{8}$. Escala, todavia, é estabelecida a partir de um padrão intervalar fixo que permite ser iniciado por qualquer nota. Ainda mais significativo é o fato de aos modos gregos serem atribuídos ethos específicos. 
Quintiliano afirma que "um ethos recai sobre os sons agudos e outros sobre os sons graves" (Cf: 1986, p.55). Monro confirma essa particularidade de o registro atuar como determinante do ethos ao citar uma passagem do capítulo 19 de "Problemas", texto atribuído a Aristóteles. Nesta, Aristóteles comenta sobre a relação que Platão entende entre os registros agudo e grave, atribuindo a estes, respectivamente, a capacidade de excitar a paixão (excitement of passion) e suavidade ou auto-indulgência (Cf: MORO, 2012, p.38).

Os tetracordes eram sempre construídos da altura mais aguda para a mais grave (diferentemente da maneira ascendente como os modos eram escritos na Renascença). Uma tentativa de explicação para essa forma de escrita descendente dos sons dos tetracordes adotada na Grécia antiga sugere que havia o entendimento que os compositores eram inspirados pelas musas, ou seja, os modos provinham do alto e eram legados de cima para baixo. Na Renascença, todavia, a música, e portanto os modos, eram maneiras de elevação das preces a Deus, o que explicaria o sentido ascendente da escrita das notas dos modos eclesiásticos. As notas extremas dos tetracordes na teoria da Grécia antiga eram consideradas como tendo altura estável, enquanto as duas notas intermediárias podiam variar conforme o gênero desejado, sendo que o intervalo inferior era geralmente menor e o superior, maior (fig. 1). No tetracorde diatônico (fig. 1a), os dois intervalos superiores eram tons inteiros e o inferior, meio-tom. No cromático (fig. 1b), o intervalo superior era um semidítono (ou terça menor) e os dois intervalos inferiores eram constituídos de meio-tons, constituindo uma zona densa chamado de pyknon. No (fig. 1c) enarmônico, o intervalo superior era um dítono (ou terça maior) e os dois intervalos inferiores do pyknon eram menores do que meios tons, podendo ser quartos de tom ou próximos de quartos de tom, porém iguais entre si. Essa variedade de relações intervalares criava matizes dentro de cada gênero (Cf: Grout e Palisca, 2001, p.23).

(a)

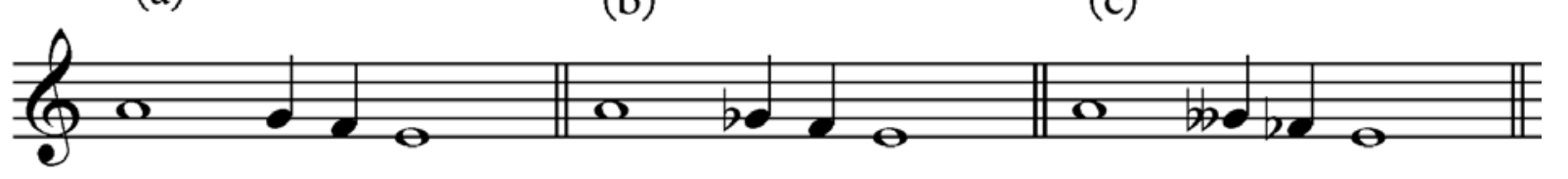

Fig. 1: Exemplos dos três gêneros básicos de tetracorde: (a) diatônico; (b) cromático; (c) enarmônico

Entretanto, alguns tratadistas do período, como Quintiliano, preconizavam um maior número de tetracordes e gêneros. Barry, baseado em Quintiliano, entende que na prática o número de tetracordes limitava-se pela diferença perceptível de "gênero, sombra e espécie" (Barry, 1919, p.579). Barry fornece exemplos de seis formas de tetracordes: diatônico normal e diatônico suave (soft diatonic); cromático normal, cromático hemiolico e cromático suave; enarmônico. Os tetracordes eram combinados de modo a constituir os modos, que se estruturavam basicamente pela junção de dois tetracordes. Esta união de tetracordes poderia formar uma escala conjunta, disjunta ou mista (ver Fig. 2a, 2b e 2c, respectivamente). Como explica Barry, que analisou diversas composições musicais da Grécia antiga, "se dois desses [tetracordes] eram combinados de modo que uma nota comum servisse como a nota mais aguda do tetracorde infe- 
rior e a mais grave do tetracorde superior, a escala resultante era conjunta, tendo uma extensão de sétima menor. Mas, se o intervalo de um tom separava os dois tetracordes, a escala era então definida com disjunta, por causa da presença do tom de disjunção. Se, entretanto, a escala conjunta fosse estendida de modo a compreender uma oitava, pela adição de um intervalo de um tom na sua base, a escala torna-se mista ou de forma alternada." (BARRY, 1991, p.580).
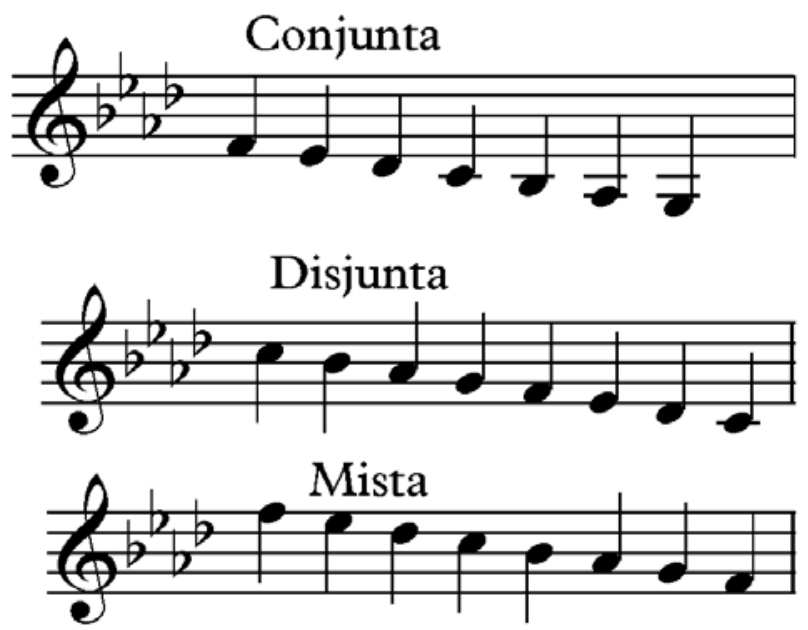

Fig. 2: Três resultantes escalares geradas pela junção de tetracordes (Barry, 1919, p.580)

A superposição dos tetracordes hypaton, meson, diezeugmenon e hyperbolaion formava o Grande Sistema Perfeito ${ }^{9}$ - systêma teleion meizon (Ver: Palisca, 2006, p.75; Matthiessen, 1999, pp.382 e 565; Monro, p.62). Cada nota tinha nome composto, por exemplo, nete hyperbolaion, em que o primeiro termo indica a posição da nota no tetracorde e o segundo era o nome do próprio tetracorde. O mese (a altura central do Grande Sistema Perfeito) e o proslambanomenos (a altura mais grave do Grande Sistema Perfeito) não recebiam nome composto. Os tetracordes eram denominados segundo a respectiva posição: hyperbolaion (alturas extremas); diezeugmenon (disjunção); meson (meio); hypaton (o último) - (fig. 3).

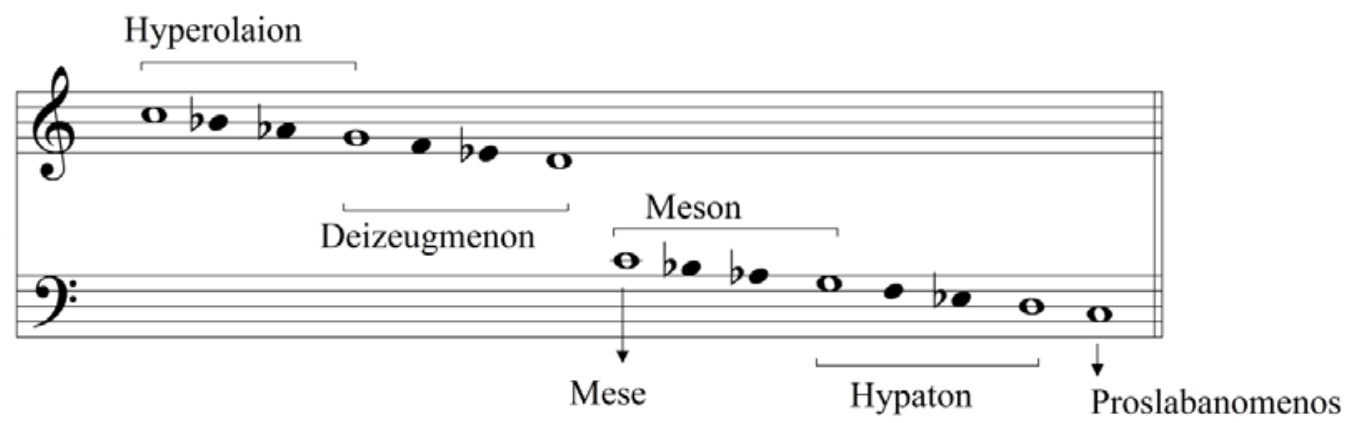

Fig. 3: formação de escalas com os diferentes tetracordes

9 Há uma imagem extraída Egert Pöhlmann (Denkmäler altgriechischer Musik, 1970) no verbete "Musical system of ancient Greece" da wikipedia, onde o leitor poderá visualizar os três sistemas engendrados pela superposição de tetracordes: Grande sistema perfeito; Pequeno sistema perfeito; Sistema perfeito imutável. 
De acordo com Grout e Palisca (2001, p.25), para Aristóxenos a palavra tonos tem "quatro significados: nota, intervalo, região da voz e altura". Ela é usada com o sentido de região da voz (registro) quando se refere ao tonos dórico, frígio ou lídio, uma vez que o registro também influenciava o ethos, como se verá adiante. No tratado Manual de

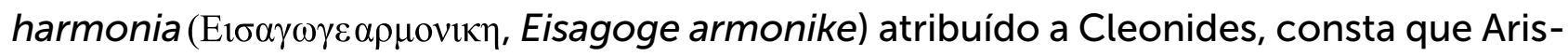
tóxenos distinguia treze tonoi que serão, a seguir, apresentados do mais agudo ao mais grave. Hipermixolídio (ou, Hiperfrígio); dois Mixolídios, um mais agudo e outro mais grave, sendo o mais agudo também chamado de Hiperiástio, e o mais grave de Hiperdórica; dois Lídios, um mais agudo e outro mais grave, sendo o mais grave chamado de Eólio; dois Frígios, sendo o mais grave chamado de lástio; um Dórico; dois Hipolídios, sendo que o mais grave pode receber o nome de Hipoeólio; dois Hipofrígios, o mais grave pode ser chamado de Hipoiástio; e por último, o tonos mais grave de todos, Hipodórico (STRUNK; TREITLER, 1998, p. 445).

O modo era, assim, caracterizado por certos atributos como o ethos, registro, gênero, as notas excluídas, as preferências étnicas (ou seja, particulares de cada nação ou tribo), entre outros, mas a cada modo estava associada uma espécie particular de oitava.

Resumidamente, as alturas formavam intervalos que geravam tetracordes que, por sua vez, constituíam gêneros diferentes, caracterizando assim os diferentes modos. Monro (2012, p.21) entende que a interpretação do sistema formado pelo conjunto desses modos é por vezes confusa, dado a divergência de nomenclatura adotas pelos autores. Aristoxenus chamava a esse conjunto de modos de tonoi, que se distinguiam basicamente pelo registro. Platão e Aristóteles, por sua vez, utilizava a palavra harmoniai, sendo a ordem dos intervalos o principal fator de diferenciação dos modos. Ainda, segundo Monro "outros autores antigos usaram a palavra tropos, de onde provém modus no latim e o inglês modo (mode) ou humor (mood)" (vide 2012, p.20). Todavia, o mais importante é notar que todos estes aspectos convergiam para o entendimento dos ethos particulares a cada modo, ou seja, espécie de conexões extramusicais que os distinguiam. Com isso, o modo dórico (de Mi3 a Mi2), por exemplo, tinha a característica de temperança, pois os elementos como a constituição intervalar e o registro produziam esse caráter.

\section{Platão e o ethos}

Entre os filósofos mais conhecidos que trataram da utilização do ethos encontramos Platão e Aristóteles. Em suas obras, como $A$ república, de Platão, e $A$ política, de Aristóteles, foram discutidas as utilizações dos modos, ritmos, palavra e a posição da música na sociedade, temas para os quais ambos apresentam semelhanças e divergências, particularmente em suas manifestações correspondentes ao ethos.

A República foi escrita por Platão cerca de 380 a.e.c. Neste livro, ele discute a respeito das demandas para garantir a administração de uma cidade de modo a mantê-la livre da anarquia e do caos. Em vista deste objetivo, são tratados temas essenciais, tais como ética, justiça, educação e felicidade. De maneira muito sumiria que $A$ República trata da constituição e gerência de uma cidade ideal. Platão, no terceiro livro d'A 
república, discorre sobre a música na sociedade, sua influência na pessoa que a escuta e o direcionamento que pode ser dado pelo executante da peça musical. Sócrates (o interlocutor habitual de Platão) diz no diálogo que a melodia de uma música possui três componentes: "as palavras, a harmonia e o ritmo" (PLATÃO 398d). ${ }^{10}$

Vale aqui um pequeno parêntesis: o conceito de harmonia na Grécia antiga dizia respeito às relações entre sons, compreendendo assim o teor de agradabilidade (ligado à estética) e ajuste (tratado pela matemática) entre dois intervalos. Em razão desse entendimento amplo de harmonia (não limitado à superposição de intervalos de maneira a gerar acordes, assim entendido a partir do final do Barroco), a afinação apropriada das cordas dos instrumentos e a constituição precisa de uma gama escalar (modo), eram também consideradas no âmbito da teoria harmônica. Aristides Quintiliano, em seu tratado De Musica, divide a totalidade da música em duas partes: teórica e prática. Segundo ele, "a parte teórica divide-se em física e técnica" (Livro I, 5, p.5). A física trata do aspecto aritmético envolvido no estudo das relações acústicas do som, como demonstrado por Pitágoras. E é exatamente por este motivo que esse parêntesis é pertinente, uma vez que Quintiliano e Platão são herdeiros do pitagorismo. Para Quintiliano a parte técnica da música compreende três elementos "harmônica, rítmica e métrica" (Livro I, 5, p.5). Esses elementos são objetos de uso (pelo criador da música) e de expressão (pelo executante). "As partes do uso são: composição melódica (melopoiía), composição rítmica (rhythmopiía) e composição poética (poiesis)" (Livro I, 5, p.6). Percebe-se, assim, que Platão e Quintiliano valem-se da mesma base tríplice para o entendimento da constituição da música: harmonia, ritmo e texto.

A partir destes elementos estruturantes, Platão discute sobre as restrições que essa arte deve sofrer de modo a adequar-se (e também contribuir) ao objetivo da constituição de sua cidade ideal. Neste sentido, a música teria a capacidade de formar, ou pelo minos, induzir um ethos apropriado à sociedade - que no discurso de Platão compreende basicamente governantes, trabalhadores e guardiões (servos e escravos não são objeto de seu escrutínio). Platão apresenta, inicialmente, as suas restrições em relação ao que pode ser cantado na letra da música, fazendo referência ao que categorizou como próprio para as histórias e contadores de histórias expressarem, proibindo versos que tratam dos deuses, filhos de deuses ou heróis, como injustos, lamentosos, libidinosos (PLATÃO 389e392a). A seguir, Platão segue o mesmo procedimento com relação aos modos, considerando aqueles que podem ser utilizados para melodias destinadas aos guardiões (guerreiros) da cidade ideal. Para a aplicação específica à educação dos guardiões, Platão não permite modos que transmitam sensações de lamento, lugubridade, suavidade ou preguiça, também não são permitidos modos indutores de lascividade e de embriaguez (PLATÃO 398d-e). Alguns modos, portanto, são considerados inadequados por Platão, que advoga pela sua necessária proibição justamente por não objetivarem ao ethos apropriado: mixolídio, lídio, jônio (PLATÃO 398e). Os modos admitidos como apropriados são o dórico e o frígio (PLATÃO 399a). O segundo deles foi escolhido 
por expressar temperança, ou seja, um modo para situações de discussões, persuasão, prece aos deuses, advertência, entre outras que gera no ouvinte bom senso e moderação (PLATÃO 399b). O primeiro foi escolhido para situações de guerra. Este tem a capacidade de gerar no guerreiro a valentia para enfrentar as batalhas (PLATÃO 399a-c).

Desse modo, no diálogo, Platão (399c) restringe a quantidade de modos que um instrumento poderia tocar, dando preferência a instrumentos com capacidade de execução de poucos modos, declaramente por julgar que apenas esses dois modos eram suficientes. Ele, assim, admite somente a lira e a cítara, na cidade, e a siringe (syrinx, ou sírinx, instrumento de sopro feito do colmo da cana - flauta de Pã), no campo (PLATÃO 399c-d).

Em seguida, Platão escreve a respeito da utilização dos pés métricos que são "correspondentes a uma vida ordenada e corajosa" (PLATÃO 399e). Os pés métricos devem submeter-se à palavra (PLATÃO 400a). Platão recorre a Damon para a escolha do pé métrico mais adequado, citando estes: dáctilo (qualificado como heroico), enoplios (possivelmente estruturado como o anapesto), iambo e troqueu, embora não atribua qualificações a nenhum dos três últimos. ${ }^{11}$ Platão (400b) também observa que há pés métricos ligados à "intolerância, insolência, loucura e outros defeitos", que devem ser evitados. Ele esclarece que Damon ao mesmo tempo "criticou e recomendou uma velocidade do pé-métrico não inferior à do ritmo em si mesmo, ou então alguma combinação dos dois" (PLATÃO 400c) ${ }^{12}$.

Para Platão, não somente o ritmo, mas também a harmonia, deve estar submetida à palavra; entretanto, a boa qualidade do texto dependerá também do ethos das músicas (400e). Para isso, Platão propõe a censura para os artistas que não executassem músicas com os caráteres considerados adequados, desse modo, estes não poderiam se apresentar na cidade ideal. Os caráteres adequados, como mencionados anteriormente, são temperança e bravura. Os caráteres inadequados foram apresentados com maior ênfase, como baixeza, insolência, loucura e indolência. (PLATÃO 401b-d).

Platão demonstra ênfase na utilização da música porque "o ritmo e a harmonia penetram mais fundo na alma e afetam-na mais fortemente, trazendo consigo a perfeição, e tornando-a perfeita" (401d), desde que o cidadão tenha sido educado conforme os ideais propostos n'A República. Desse modo, Platão mostrou os aspectos considerados como influentes sobre o caráter humano e utilitários para a sua cidade ideal. Assim, o caráter adequado deve reger o tipo de harmonia, ritmo e discurso que deve ser utilizado, caso contrário, incorrer-se-ia na incapacidade de julgar aquilo que é ou não justo.

\section{Aristóteles e o ethos}

Aristóteles apresenta uma maior flexibilidade na abordagem do ethos na música. Veremos que ele segue muitas ideias de Platão, mas as suas contraposições são diretas e

\footnotetext{
11 Thomas Mathiesen (STRUNK; TREITLER, 1998, p. 13n17), seguindo um comentário anterior de Oliver Strunk (na edição original de Source readings, 1950, p. 6n7), indica que o pé métrico enoplios apresentaria uma caráter (ou poder de indução) bélico.
} 
até contundentes. Trataremos agora d'A Política de Aristóteles ${ }^{13}$, um dos seus livros mais importantes. Como pode ser deduzido pelo título: política (polis = cidade), Aristóteles considera assuntos relativos ao funcionamento da cidade. Comentadores entendem que o assunto principal da Política é a busca da felicidade humana, ou seja, o estabelecimento de uma estrutura de comportamentos sociais a serviço de uma modo de vida orientado ao encontro da felicidade humana. "Aristóteles determina o propósito da conduta humana (a felicidade), a partir da natureza racional do homem, e depois determina as virtudes que são condição da felicidade" (ABBAGNANO, 2007, p.380). Percebe-se, assim, que temas prementes como ética, educação e razão são abordados por Aristóteles, e no que diz respeito à virtude humana o assunto necessariamente abarca o conceito de ethos.

No livro oito d'A Política, Aristóteles reflete sobre a educação e principalmente a respeito do papel da música no Estado. Ele inclui a música entre os quatro pilares da educação do Estado, a saber: leitura e escrita, ginástica, música e desenho. Esta inserção, todavia, é objeto de questionamentos, sobretudo no que diz respeito à função social da música, uma vez que esta, por si, não é, a princípio, tão útil como a leitura e a escrita (necessárias para o gerenciamento doméstico e dos negócios, e também necessários para aquisição de conhecimento), como a ginástica (que ajuda a manter o corpo saudável) ou o desenho (que serve para entender e apreciar a arte) (ARISTÓTELES 1338a1520). Tendo este questionamento como ponto de partida, Aristóteles passa a apresentar argumentos no sentido de entender e justificar a presença da música como fundamento da educação do Estado. A primeira proposta é de que a música deve ser utilizada durante os períodos de lazer, promovendo assim um entretenimento intelectualizado para as crianças quando se tornarem adultas. Note-se que o lazer compreende todo o tempo que não é dedicado ao trabalho. Desse modo, mesmo o estudo da música de modo sério é considerado como entretenimento. Para Aristóteles, o tempo de lazer é fundamental para o descanso físico e mental, e segundo ele "aquele que estiver arduamente trabalhando tem necessidade de relaxamento, e diversão fornece relaxamento, enquanto a ocupação é sempre acompanhada de fadiga e esforço" (ARISTÓTELES, 1338a4) $)^{14}$.

Mais à frente, Aristóteles levanta a possibilidade de a música ter efeito no caráter do ouvinte. Na tentativa de provar sua afirmação, Aristóteles argumenta que as canções do músico Olimpo de Mísia "inspiram entusiasmo, e entusiasmo é uma emoção da parte ética da alma" (ARISTÓTELES 1340a1015). Ele aprofunda sua exposição falando que "ritmo e melodia fornecem imitações de raiva, graciosidade, coragem, temperança e outros tipos de virtudes e vícios" [...] "essas raramente se afastam das emoções reais, pelo fato de, enquanto escutamos músicas que nos afetam, nossa alma sofre alterações" (ARISTÓTELES 1340a1525). Percebemos, portanto, que o conceito de ethos funciona como objetivo da obra artística, sendo o pathos resultante da apreciação da mesma.

\footnotetext{
13 Todas as citações da Política de Aristóteles foram extraídas da tradução ao inglês de Benjamin Jowett, The Politics of Aristotle de 1885.

14 "for he who is hard at work has the need for relaxation, and amusement gives relaxation, whereas occupation is always accompanied with exertion and effort"
} 
Assim sendo, Aristóteles fez a seguinte comparação em relação às sensações reais e aquelas despertadas por meio da apreciação da arte: "O hábito de sentir dor ou prazer em relação a representações não está distante das sensações relativas as suas formas reais, já que, o prazer de observar uma escultura, se não for alterada, necessariamente leva ao prazer de observar o original" (ARISTÓTELES 1340a2530).

Aprofundando esse raciocínio, ele mostra que em melodias há a imitação de caráter por meio dos modos. Para demonstrar, ele cita alguns destes, como o mixolídio, que afeta as pessoas ao lamento (ou lugubridade, como em Platão) ou à austeridade, o dórico, que produz um temperamento de suavidade e calma, e o frígio, que provoca sufusão divina (ARISTÓTELES 1340a40b10). Aristóteles expõe que "de forma semelhante, algo ocorre com o ritmo, que pode provocar a sensação de repouso e de movimento" (ARISTÓTELES 1340b515).

Tendo isso em mente, Aristóteles sugere que além de ser apreciada, a música deve ser executada, pois há uma considerável diferença no caráter de quem ouve a arte e de quem a executa (ARISTÓTELES 1340a40b1). Com isso, ele sugere que a execução musical gera apropriação do conteúdo da música. Essa apropriação, na fase adulta, será empregada para se promover o julgamento a respeito de qual música deve ser usada para o entretenimento. $O$ autor sugere que o aluno deve estudar até sentir "prazer nas melodias e ritmos nobres, não apenas na parte comum da música" (ARISTÓTELES 1341a15) em que qualquer um sentiria prazer. Porém, a criança deve parar seus estudos antes de alcançar o nível profissional, porque nem todos devem se dedicar profissionalmente à música (ARISTÓTELES 1340b3540, 1341a10).

Fica claro que a intenção de Aristoteles é que ao estudar o instrumento, a pessoa irá adquirir conhecimento que permitirá além de sua fruição um melhor juízo sobre a sua beleza. Desse modo, o aprendizado prático do instrumento, mesmo que em nível básico, forma uma base para o bom julgamento estético.

Estendendo suas concepções, Aristóteles nos apresenta os instrumentos musicais moralmente inadequados à educação e mostra suas observações acerca dos modos. Para ele, os instrumentos que exigem grande habilidade de execução, como o aulos e a kithara, não devem ser utilizados para a educação, a menos que haja alguma justificativa educacional (ARISTÓTELES 1341a1520). Sobre o aulos, Aristóteles ilustra: "o aulos não é um instrumento que tem bom valor moral, pois ele é muito excitante, portanto, a sua melhor utilização é em momentos de alívio de emoções fortes por meio de músicas que imitam as mesmas emoções, não no ambiente educacional" (ARISTÓTELES 1341a2025). Além do aulos, outros instrumentos foram rejeitados, como a harpa lídia, a lira, sambuca (também um tipo de harpa triangular) (ARISTÓTELES 1341a40b1), lembrando que a harpa foi aprimorada desde o tempo de Platão, permitindo, consequentemente, uma maior extensão e maior gama de habilidades técnicas pelo executante decorrentes da nova organologia desse instrumento, menos limitantes, portanto.

Aristóteles, também, vai de encontro a Platão por ele permitir a utilização do modo frígio uma vez que este modo possui o caráter de excitação estésica, (ARISTÓTELES 1342a30b5). Logo, os modos que podem ser aceitos na educação são principalmente os de cunho contemplativo, como o dórico. Entretanto, para o entretenimento 
de pessoas com menos educação musical, poderá ser tocado o modo que for do interesse destas, bem como os instrumentos por elas desejado (ARISTÓTELES 1342a1530).

A relação dos modos com a métrica da poesia é intrínseca. Aristóteles ilustra essa relação contando a tentativa de Filoxeno de escrever uma história em forma de ditirambo, poema dedicado a Dionísio, fazendo uso do modo dórico, e completando que isso se mostrou impossível, pois a métrica e o modo utilizados não tinham relações próximas de caráter. Para resolver isso, Filoxeno mudou seus ditirambos do modo dórico para o frígio (ARISTÓTELES 1342b515).

Na última parte do livro, Aristóteles propõe que a utilização da música deve ser correspondente à idade, sendo que os idosos podem executar as melodias mais suaves; as crianças, as melodias direcionadas à ordem e à educação, como o dórico, citado várias vezes, e o lídio; e o adulto deve adequar seu entretenimento ao seu conhecimento (1342b20[35]). A música, por fim, deve corresponder à necessidade do ouvinte em três aspectos: educação, entretenimento e alívio emocional da alma. O último, realizado principalmente pelos cidadãos desprovidos de educação musical. Para Aristóteles, a presença da música na educação ocorre principalmente pela relação que a música tem com as emoções, que pode ser chamada de movimento da alma. A partir dessas concepções apresentadas por Platão e Aristóteles, correlacionaremos, a seguir, esses autores e responderemos mais diretamente as perguntas formuladas no início deste texto.

\section{Ferramentas para transmissão do ethos}

Em Platão, observamos uma preocupação ética clara na base de suas afirmações sobre ethos e, consequentemente, na música, pelo fato de a música apropriada ter o "poder" de incitar à temperança e à bravura. Enquanto que, em Aristóteles, ainda que haja preocupação ética, os focos estão nas necessidades dos cidadãos, ou seja, entretenimento, alívio emocional e a educação dos jovens. Com isso, compreendemos a diferença entre esses filósofos em relação aos seus entendimentos sobre a função da música na sociedade: em Platão tem-se a música a serviço do Estado, usada para a manipulação da população, enquanto em Aristóteles a música tem seu uso enquanto veículo de pedagogia, entretenimento e catarse. Apesar dessas distintas concepções, ambos os filósofos se valeram das mesmas ferramentas para transmitir o ethos desejado, ou seja: o modo, o instrumento, o ritmo e a palavra.

A primeira ferramenta de transmissão de ethos a ser discutido será o modo. Para entender melhor como um modo pode alterar um caráter devemos considerá-los em suas partes constituintes. De acordo com Grout e Palisca (2001, p. 22-23), o modo pode ser desconstruído em gêneros, depois em intervalos e por último em notas. Sobre os gêneros de tetracordes, como citado anteriormente, vimos que estes podem indicar caráter: o diatônico era viril, o cromático, lamentoso e o enarmônico, corajoso (ANDERSON; MATHIESEN, 2016, I8). Partindo dessas ideias, podemos dizer que a sequência de intervalos constituintes dos gêneros define os caráteres, já que a altura isolada é estática, e o ethos lida com a emoção que pode ser entendida como movimento da alma. Sendo assim, a altura (isolada e estática) não poderia gerar movimento, portanto ela não 
impingiria um ethos. Isso implica que, para que haja a transmissão do ethos desejado, deve-se fazer uso das relações intervalares organizadas para tal, como podemos encontrar nos modos. Confirmando esta compreensão, mencionamos uma passagem de Plutarco:

\begin{abstract}
Plutarco argumenta que o pequeno número de notas nos modos usados pelos músicos anteriores não surgiu por ignorância, mas era característico de sua arte, e necessário ao seu ethos peculiar. Entre outros pontos, ele notou que o tetracorde Hypatôn não foi usado na música Dórica (en tois Dôriois) e isto, ele diz, não se deveu ao fato de eles desconhecerem esse tetracorde, pois eles usaram-no em outros modos (tonoi). Contudo, eles o deixaram de fora no modo Dórico com intenção de preservarem o seu ethos, uma beleza que eles valorizavam (Plutarco, apud MONRO, 2012, p.49) ${ }^{15}$.
\end{abstract}

Para um entendimento aprofundado sobre o papel das relações intervalares no ethos de cada modo particular seria necessário um estudo do primeiro seguimento da teoria pitagórica sobre a manipulação numérica da música: a utilização abstrata de relações harmônicas e de valores cósmicos. Todavia, esse assunto extenso e a sua matemática intrínseca estão além do escopo deste texto. Não obstante, é possível perceber a projeção do conceito de ethos nos modos. De acordo com o pensamento platônico, por exemplo, esta projeção implicou na permissão somente dos modos que gerassem as emoções desejadas, ou seja, temperança e bravura. Em relação aos gêneros de tetracordes, Platão não aponta um deles como o melhor ou aquele que deve ser utilizado, porém, não seria descabido afirmar que ele excluiria o gênero cromático e permitiria somente o diatônico e enarmônico, uma vez que o gênero "diatônico era considerado masculino e austero (arrhenôpon d' esti kai austêroteron), o cromático amável e lamentoso (hêdiston te kai goeron), o enarmônico agitado e agradável (diegertikon d' esti touto kai êpion)" (Aristides Quintiliano, apue MONRO, 2012, p.97). A prescrição de Platão visava ao controle dos caráteres dos guardiões.

Em relação a Aristóteles, a variedade de emoções advindas da diversidade de modos era bem-vinda, sendo cada modo utilizado para uma situação particular: educação, entretenimento, ou diversão. Aristóteles ressalta ainda que as melodias de melhor caráter devem ser apreciadas e cultivadas na educação pela elite intelectual dos cidadãos, concordando com sua visão da utilização menos restritiva da música.

A segunda ferramenta a ser tratada será o instrumento musical. Na literatura consultada, nota-se que os filósofos consideram apenas dois tipos de instrumentos musicais com capacidade de produzir efeito no sentido de ethos: os intrumentos de cordas e os de sopro. Tanto nos textos de Platão quanto nos de Aristóteles, encontramos que os instrumentos de cordas com extensão pequena são preferidos aos de sopro ou até mesmos aos de muitas cordas, com exceção da sírinx. Vimos que, de acordo com os mesmos autores, a preferência pelos instrumentos de cordas ocorre por estes não te-

\footnotetext{
15 Plutarch is contending that the fewness of the notes in the scales used by the early musicians did not arise from ignorance, but was characteristic of their art, and necessary to its peculiar ethos. Among other points he noticies that the tetrachord Hypatôn was not used in Dorian music (en tois Dôriois), and this, he says, was not because they did not know of that tetrachord, for they used int in other keys (tonoi) - but they left it out in the Dorian key for the sake of preserving its ethos, the beauty of which they valued.
} 
rem o caráter de êxtase presente nos instrumentos de sopro. A indicação da extensão pequena dos instrumentos possivelmente se deve a questões de registro, ou seja, no âmbito do Sistema Perfeito, o registro intermediário era preferido, e também ao fato de os autores não considerarem a necessidade do virtuosismo técnico aplicado ao instrumento, provavelmente por demandar tempo de estudo do instrumentista, tempo este que poderia ser utilizado em outras atividades mais necessárias para a formação humana da época. Outra possibilidade em relação à especificação da extensão é que, sendo ela pequena, a alteração do modo dificulta-se, tornando assim impossível a mudança do ethos no decorrer da música. Desse modo, a escolha do instrumento implicaria na possibilidade de alteração do caráter da música entre êxtase e moderação; mas, a transmissão desse caráter ainda se encontraria subordinada aos efeitos do modo escolhido.

Em relação a Platão, a escolha dos instrumentos coincide com suas ideias para a construção de sua cidade ideal, apesar de ele não admitir a utilização da sirinx. A impossibilidade de mudar de ethos durante a música reforça a imposição do ethos desejado à quem se direcionava tal música. Apesar de o virtuosismo ser visto com ressalvas por Platão, poder-se-ia também aventar uma interpretação de que essa prescrição é apenas parcial, ou seja, não extensiva a todos os cidadãos, já que cada um deveria dedicar-se a um trabalho e executá-lo da melhor maneira possível. Dessa maneira, aquele que se dedicar à música deveria despender do tempo necessário para tornar-se um bom executante, não havendo, então, excesso ou desperdício de tempo gasto neste afazer.

Aristóteles segue um pouco próximo a Platão no que diz respeito à educação dos jovens pela música. Dessa maneira, ele permite o uso de instrumentos somente para finalidades didáticas, sem impor restrições aos cidadãos ou população de classes inferiores, pois estes poderiam escutar os instrumentos quando fosse adequado às situações citadas anteriormente, embora a música com ethos utilizados para os cidadãos não seja mencionada como uma possibilidade para essa população menos privilegiada.

A terceira ferramenta de transmissão do ethos é o ritmo. O ritmo apresenta capacidade de representar diferentes ethos e afetar o caráter de uma pessoa de forma semelhante aos modos. A variedade de pés métricos auxilia a diversidade de caráteres transmitidos. Ambos os autores citam os efeitos que o ritmo pode gerar (e.g., coragem, tristeza, temperança). Entretanto, nos textos de Platão e Aristóteles mencionados, os autores não designam ou associam diretamente caráteres específicos a cada pé métrico, como por exemplo o troqueu tem um ethos X. Mas a consulta à situações em que tais pés métricos foram comumente utilizados pode indicar essa associação. Por exemplo, o anapesto (construído de duas sílabas curtas átonas e uma longa tônica) era usado em marchas espartanas. Desse modo, a associação desse pé métrico com o ethos de bravura, coragem ou mesmo pompa e solenidade é totalmente viável. Quintiliano, ao comentar a origem dos nomes dos pés métricos, diz: "o espondeu [foi assim nomeado] porque era cantado nas cerimônias de libação [que eram chamadas de spondai]; e o jônio pela vulgaridade do ritmo, motivo pelo qual os Jônios também foram ridicularizados" (1996, p.89).

Dáctilo, anapesto, iambo e troqueu foram os pés métricos citados no livro três $d$ 'A República de Platão. O dáctilo significa, com base em sua etimologia, dedo (QUINTILIANO, 1996, p.89; FARRELL, 2016) que, se olharmos para as falanges do dedo partindo 
da palma da mão, veremos a relação de notas longas e curtas (longa, curta e curta). Esse era usado em recitativos e poemas épicos (RIBEIRO, 2016). O anapesto significa, com base em sua etimologia, bater ou batalha, e tem sua estrutura rítmica parecida com o galopar de um cavalo (curta, curta e longa). A métrica anapéstica era utilizada tanto na comédia como na tragédia, porém, na última, principalmente em momentos característicos como o retorno de algum exilado (PASQUALI, 2016a). Beethoven fez uso desses pés métricos no primeiro movimento de sua Sétima Sinfonia, alternando entre dáctilo e anapesto no acompanhamento do solo de trompa que executa o primeiro tema dessa forma sonata (Fig. 4). Alguns dicionários etimológicos propõem que iambo significa "mover adiante", "empurrar para frente"16, e também tido como jocoso e sarcástico, "o metro crítico e satírico no grego clássico". O iambo estrutura-se metricamente com o padrão curto e longo. Gilbert Rouget, ao versar sobre o ditirambo, enfatiza a associação deste gênero poético com o culto a Dionísio, para a seguir comentar "como gênero poético, somos informados que era [o ditirambo] essencialmente iâmbico" (Rouget, 1985, p.79) ${ }^{17}$.

O troqueu pode ser entendido etimologicamente como corrida ou dança, com sua forma rítmica sendo longo e curto. Utilizado tanto na comédia quanto na tragédia, nesta, porém, em menor grau. O caráter original, como pode ser entendido por seu nome, era de velocidade e leveza (PASQUALI, 2016b).

Grosvenor Cooper e Leonard Meyer (1960, p. 6) basearam seu trabalho a respeito da estrutura rítmica da música nos pés métricos da prosódia grega. Os autores partem da seguinte definição de ritmo: "a maneira na qual um ou mais pulsos não acentuados são agrupados em relação a um pulso acentuado" ${ }^{18}$. A seguir, os autores apresentam cinco possibilidades de combinação entre esses agrupamentos ( $u=$ curta, _ = longa):
a) Troqueu $=_{-} u$
b) lambo $=u_{-}$
c) Dáctilo: _ u u
c) Anapesto $=u_{-}$
d) Anfíbraco: u_u

\footnotetext{
16 Veja-se, por exemplo, o verbete "lamb" no Online Etymology Dictionary: "to assail, attack" (in words), literally "to put forth, send forth". The meter of invective and lampoon in classical Greek since it was first used 7c. B.C.E. by Archilochus" (http://www.etymonline.com/index.php?term=iambic)

17 We know from other sources that the dithyramb was originally closely associated with Dionysiac rituals. And, as a poetic genre, we are told that it was essentially iambic"

18 Rhythm may be defined as the way in which one or more unaccented beats are grouped in relation to an accented one.
} 


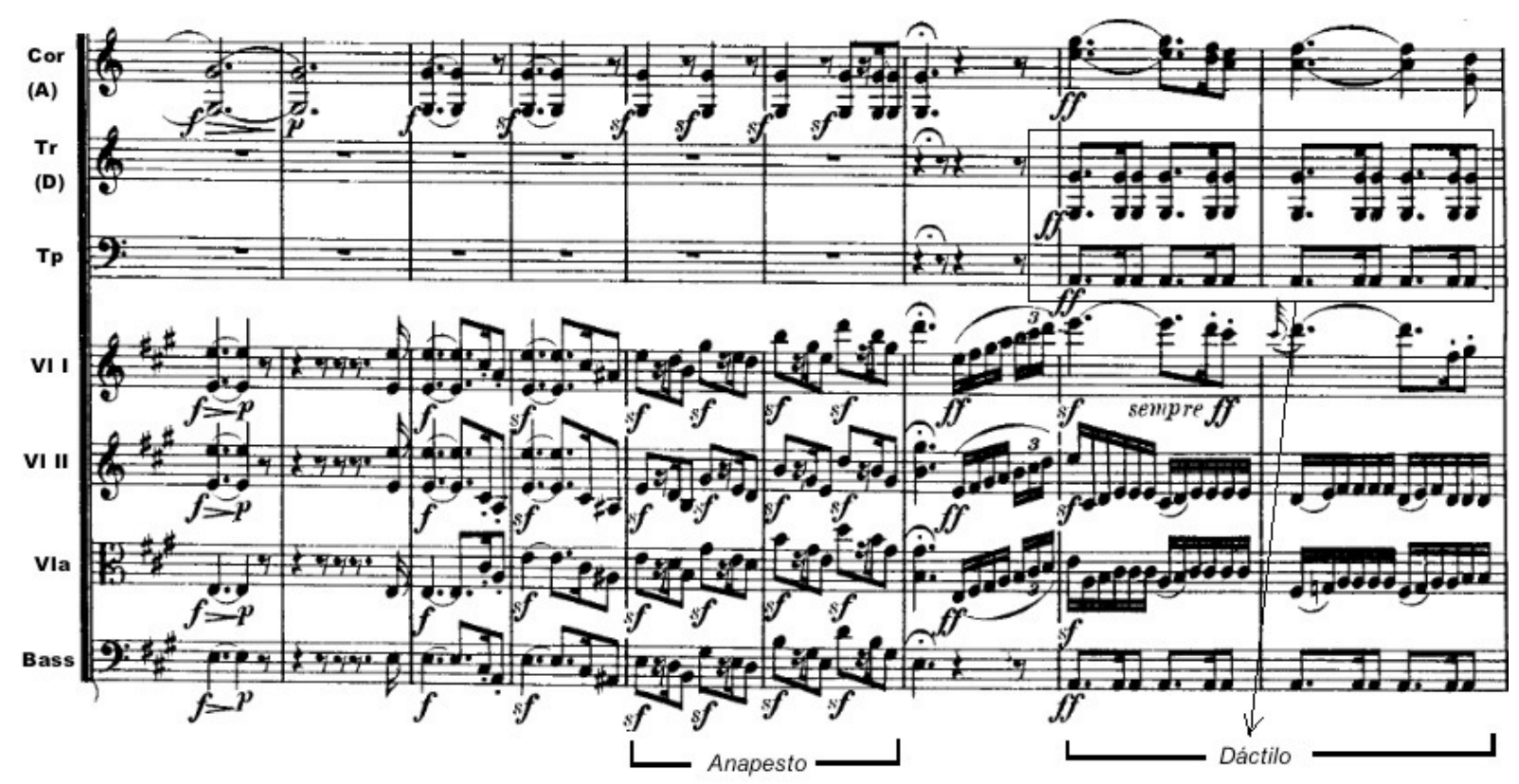

Fig. 4: Beethoven, excerto da Sinfonia No. 7, I. Uso dos pés métricos dáctilo e anapesto.

Não encontramos, todavia, nos textos de Platão e Aristóteles referência ao Anfíbraco. Nestes textos, nota-se que o dáctilo era o único modo rítmico não característico das comédias, sua utilização foi majoritariamente encontrada em poemas épicos que narravam histórias de heróis. Com isso, o dáctilo se apresenta como o pé métrico mais elevado entre os citados. As suas características diferenciais são o comprimento, ou seja, trissílabo e portanto maior do que o iambo e troqueu, ambos dissílabos) e início tético (diferenciando-se, assim, do anapesto, que também é trissílabo, porém com início anacrúsico). O tamanho e o início longo dão ao dáctilo um caráter recitativo que é funcionalmente apropriado para o entendimento do caráter do texto. Para Platão, o dáctilo apresenta-se como o pé métrico perfeito, pois a compreensão do texto na sua forma recitada era o que ele desejava. Possivelmente, Platão também incluiria o anapesto para os momentos de guerra por ser característico dessas situações.

A palavra é a última ferramenta para transmissão de ethos a ser aqui considerada. O ethos na palavra é pensado no mesmo sentido que nos outros meios, ou seja, com a intenção de transmitir um caráter específico. Platão, n'A República (389e 392a), escreve os tipos de caráteres que não são permitidos em relação à palavra. Na sua cidade ideal, não é permitido contar histórias que mostrem baixeza, luxúria e vícios em geral por parte das personagens. Em Aristóteles, é mostrado um caso em que o texto não tinha relação com o modo escolhido, que o autor acabou mudando para estabelecer melhor correspondência entre o ethos do texto e o modo (o texto era um ditirambo, para o qual Filoxeno havia pretendido uma melodia segundo o modo dórico, mas foi compelido a modificar para o modo frígio). A transmissão do caráter na palavra ocorre por meio do sentido das frases. Apesar de algumas palavras poderem direcionar mais imediatamente o caráter a ser veiculado, como as palavras pertencentes à classe dos adjetivos, por exemplo, o sentido total da frase especifica o ethos, pois há que se considerar o 
encadeamento sintático de todo período (que contem diferentes classes gramaticais) na formação de um ethos específico. Alguns autores enfatizam que a palavra tem valor hierárquico maior que os modos, o ritmo e os instrumentos. Isto é afirmado diretamente por Platão (400e) e demonstrado no exemplo mencionado por Aristóteles (1342b5 15) do ditirambo que teve seu modo alterado. Com isso, entende-se que o valor do ethos na palavra encontra-se no sentido semântico e que os outros meios devem, portanto, subordinar-se a esse sentido.

Em Platão (398d), a música não era separada da palavra e, por isso, a utilização correta das palavras influenciava o caráter das músicas. Assim, o maior controle do ethos encontrava-se no rigor da escolha do conteúdo dos temas tratados e, portanto, no domínio com que os poetas executam seus textos. Com essa observação, Platão nos fornece, em relação às restrições de modo, ritmo e instrumento, um tratado superficial de como a música deveria ser criada e executada em sua cidade ideal. Comparando-se com a música atual, percebe-se que o caráter de uma obra musical é ainda distinguido mais diretamente pela letra cantada, e só secundariamente pelo acompanhamento instrumental.

\section{Conclusão}

A partir do exposto por meio da literatura consultada, constata-se que o ethos é um conceito que afeta os ouvintes por meio dos modos, do ritmo, do instrumento e, mais diretamente, do texto. A utilização de diversas relações intervalares, bem como de distintos valores de durações dos sons, timbres e de palavras modificam a intencionalidade do caráter da obra conforme pretendido pelo autor. Para Platão, o compositor deveria ser livre para compor peças que transmitissem à população emoções de elevada virtude moral. Ele proíbe a composição sem compromisso com a ética da sociedade e, para tanto, atribui à música uma função importante, pois, consequentemente, ao músico caberia a responsabilidade pela formação moral da sociedade. No entanto, Platão restringe os materiais composicionais disponíveis para o músico a um número pequeno de elementos, ou seja, aos modos dórico e frígio, aos instrumentos de cordas, aos ritmos que transmitem virtudes e aos textos que tratassem da grandeza dos deuses ou heróis. Essas restrições, apesar de objetivarem o desenvolvimento moral da sociedade, obviamente impõem limites e obstáculos para o músico e, de certa forma, também à sociedade, pois esta fica alijada da escuta de uma música mais elaborada, que poderia promover o progresso intelectual dessa sociedade. Nesse sentido, poder-se-ia indagar se essas restrições são de fato justificadas quando implicam no desenvolvimento da arte na sociedade. A autonomia do músico deve ser preservada no intuito de expandir os horizontes artísticos mesmo que essa ampliação possa evidenciar a transgressão às normas estabelecidas na tradição artística e, por conseguinte, aos costumes vigentes? Colocado de outro modo: as mudanças estéticas deveriam ser bem vindas mesmo implicando em nova atitude ética?

Aristóteles, por sua vez, propõe uma sociedade menos restritiva e abre possibilidade da coexistência das músicas mais e menos virtuosas. Ele entende que a educação dos jovens pode seguir os moldes platônicos, mas com a retirada do modo frígio. Todavia, permite à população a liberdade de escolha do tipo de interação que quiser ter com a 
música: alívio emocional, entretenimento intelectual ou relaxamento. Sua proposta, portanto, transforma o peso social da música como meio de desenvolvimento social doutrinador para uma espécie de terapia ou atividade de lazer.

Apesar da aparente diminuição de status que a música sofreu na passagem da sociedade de Platão para a de Aristóteles, nota-se que em Platão a música não é concebida como revestida de uma possibilidade individual de escolha e acaba por acolher um sentido mais coletivo. Já em Aristoteles, a música adquire certo sentido para o indivíduo, justamente por contemplar uma relação pessoal de escolha.

Assim, o ethos na música era considerado uma ferramenta importante na sociedade da Antiguidade Clássica da Grécia, tendo o poder de moldar o caráter e transmitir emoções à população para fins políticos, para alívio terapêutico das aflições, e mesmo para entretenimento ou simples relaxamento.

Não obstante as prescrições platônicas e aristotélicas, é necessário mencionar que a atribuição de caráteres específicos para cada modo não é consenso na literatura. Claude Palisca (1990, p. 129-130), por exemplo, apontou diferentes associações entre os modos e seus respectivos caráteres em diferentes autores e em diferentes épocas. Desde o período grego clássico, passando pela Roma antiga e Idade Média até chegar à Renascença, os autores trocaram os nomes dos modos; contudo, mantiveram o ethos associado ao nome original. Desse modo, um modo com uma constituição intervalar específica (dórico de Mi' a Mi, por exemplo) foi alterado para Ré a Ré', cuja estrutura interna de tons e semitons é diferente do padrão intervalar do modo dórico grego. Dessa maneira, o dórico grego tornou-se o frígio (deuterus) litúrgico da Renascença. Contudo, o caráter intrínseco a cada modo foi mantido. Com isso, nos modos gregos e eclesiásticos, o modo dórico (protus) continuava associado à temperança. Entretanto, a estrutura intervalar particular do modo dórico nestes dois períodos era distinta, o que necessariamente alteraria o ethos do modo.

A origem dessa confusão entre as nomenclaturas dos modos gregos e eclesiásticos é incerta. Todavia, os editores da Enciclopédia Britânica atribuem ao monge Hucbald (840 - 930) a aplicação incorreta dos nomes dos modos gregos aos modos eclesiásticos ${ }^{19}$. Claude Palisca, por sua vez, menciona que Franchino Gaffurio, após leitura da República de Platão e da Política de Aristóteles, "assumiu que os modos que eles descreviam eram mais ou menos os mesmos que os correspondentes designados como modos litúrgicos e que os poderes emocional, moral e ético discutidos pelos filósofos poderiam também ser atribuídos aos modos litúrgicos"20" (PALISCA, 2006, p.73).

Essa transformação de sistemas modais demonstra a maleabilidade ou a arbitrariedade na associação de um caráter específico a um modo particular e, por analogia, podemos dizer que o ritmo e a instrumentação também possuem essa arbitrariedade, já que estes também eram considerados dentre os aspectos necessários à elaboração de uma boa composição que transmitisse virtudes. Todavia, a carga subjetiva atribuída

\footnotetext{
19 No verbete "church modes" lê-se: The application, or rather misapplication, of the Greek names dates from a 9th-century treatise attributed to the monk Hucbald.

20 Franchino Gaffurio [...] assumed that the modes they described were more or less the same as the correspondingly named as church modes and that the emotional, moral, and ethical powers the philosophers discussed could also be attributed to the church modes.
} 
aos ethos dos diversos modos não elimina a capacidade objetiva de a música expressar caráteres diversos, basta atentar, por exemplo, aos procedimentos adotados pelos os compositores ao longo da história para representarem diferentes emoções e situações (veremos estratégias composicionais similares adotadas por diferentes compositores para tratarem de temas correlatos. Para citar um único exemplo, nota-se a semelhança na maneira como Bach (em suas Paixões) e Beethoven (na Missa Solemnis) representam temas como crucificação, morte e ressurreição de Jesus Cristo). O que ocorreu, no que se relaciona ao ethos ao longo das eras, é uma soma de possibilidades de a mesma música ter entendimentos diferentes em contextos temporais e étnicos diversos.

\section{Referências}

ABBAGNANO, Nicola. Dicionário de Filosofia. Tradução: Ivone C. Benedetti. Sao Paulo: Martins Fontes, 2007.

ANDERSON, Warren; MATHIESEN, Thomas J. Ethos. In: Grove music online. Oxford music online. Disponível em: http://www.oxfordmusiconline.com/subscriber/article/grove/ music/09055. Acesso em: 01 jan. 2016.

[ARISTÓTELES] ARISTOTLE. The politics of Aristotle. Trad. em inglês: Benjamin Jowett. Oxford: Clarendon, 1885.

BARRY, Phillips. Greek Music. In: The Musical Quarterly, Vol. 5, No. 4 (Oct., 1919), pp. 578-613. Oxford University Press. Disponível em: www.jstor.org/stable/738129/Acesso em 18 de setembro de 2017.

COOPER, Grovenor W.; MEYER, Leonard B. The rhythmic structure of music. Chicago: University of Chicago Press, 1960.

Church Mode. In: Encyclopaedia Britannica Online. Disponível em: https://www.britannica.com/art/church-mode. Acesso em 10/09/2017.

FARRELL, Joseph (coord.). Glossary. In: Hexametrica. Disponível em: http:// www .skidmore.edu/academics/classics/courses/metrica/glossary.html\#dactylichexameter. Acesso em: 29 set. 2016.

GROUT, Donald J.; PALISCA, Claude V. A situação da música no fim do mundo antigo: a herança grega. In: . História da música ocidental. Trad.: Ana Luisa Faria. Lisboa: Gradiva, 2001. cap. 1, p. 1654.

lambic. In: http://www.etymonline.com/index.php?term=iambic. Acesso em 10/09/2017. 
MATHIESEN, Thomas J. Apollo's Lyre: Greek Music and Music Theory in Antiquity and the Middle Ages. Nebraska: University of Nebraska Press, 1999.

MONRO, David Binning. The Modes of Ancient Greek Music. London: Oxford University Press Warehouse, (ebook disponibilizado online em) 2012.

PALISCA, Claude V. Mode and ethos in the Renaissance. In: LOCKWOOD, Lewis; ROESNER, Edward. (ed.). Essays in musicology: a tribute to Alvin Johnson. Philadelphia: American Musicological Society, 1990. cap. [7], p. 126139.

PALISCA, Claude V. Music and Ideas in the Sixteenth and Seventeenth Centuries. Chicago: Universtiy of Illinois Press, 2006.

PASQUALI, Giorgio. Anapesto. In: TRECCANI Cultura. Treccani, la cultura italiana: enciclopedia italiana (1929). Disponível em: http://www.treccani.it/enciclopedia/anap esto_ (Enciclopedia-Italiana)/. Acesso em: 25 set. 2016a.

PETERS, Francis E. Termos filosóficos gregos: um léxico histórico. 2. ed. Trad.: Beatriz Rodrigues Barbosa. Lisboa: Fundação Calouste Gulbenkian, 1983.

Trocheo. In: TRECCANI Cultura. Treccani, la cultura italiana: enciclopedia italiana (1937). Disponível em: http://www.treccani.it/enciclopedia/trocheo_\%28Enciclopedia-Itali ana\%29/. Acesso em: 25 set. 2016b.

PLATÃO. A república. 4. ed. Trad.: Maria Helena da Rocha Pereira. Lisboa: Fundação Calouste Gulbenkian, 1983.

QUINTILIANO, Aristides. Sobre la música. Tradução ao espanhol e comentários de Luis Colomer e Begoña Gil. Madrid: Editorial Gredos, 1996.

RIBEIRO JR., Wilson A. O verso épico. Publicação em: 19 maio 1999. In: Graecia antiqua. Disponível em: <http://greciantiga.org/arquivo.asp?num=0161>. Acesso em: 29 set. 2016.

ROUGET, Gilbert. Music and Trance: a theory of the relations between music and possession. Tradução ao inglês de Brunhilde Biebuyck. Chicago: University of Chicago Press, 1985.

SANTIAGO, Emerson. Antiguidade clássica. In: INFOESCOLA Serviços em Informática Ltda. Infoescola: navegando e aprendendo. Disponível em: http://www.infoescola. com/ historia/antiguidade-classica/. Acesso em: 10 maio 2017.

STRUNK, Oliver; TREITLER, Leo (ed.). Source readings in music history. ed. rev. New York: W. W. Norton, 1998. 